\title{
Letramento acadêmico e oralidade: repensando termos à luz da presença indígena nas universidades brasileiras
}

\author{
Maria Sílvia Cintra Martins*
}

\begin{abstract}
Resumo
Este trabalho comporta reflexões baseadas em pesquisa a respeito do letramento acadêmico, tendo em vista a realidade contemporânea brasileira da presença indígena nas universidades. Baseamo-nos, em parte, em pressupostos presentes nos Estudos do Letramento e, de forma complementar, em concepções presentes nos Estudos de Tradução. A pesquisa a que aludimos deu-se nos anos de 2012 a 2015, através de procedimentos e estratégias semelhantes àquelas presentes no que Lea e Street (2006) denominam "Academic Literacies Model”. Com base em pesquisa de viés participativo e empoderador (CAMERON, 1992), tivemos como objetivos: a) compreender como se dá a transição/tradução do gênero do discurso do relato ("récit") para os gêneros do discurso acadêmico; b) propiciar que graduandos indígenas tivessem o acesso às práticas da escrita acadêmica, em conjunto com a reflexão necessária a esse respeito. Os resultados apontam não apenas para o modelo dos Letramentos Acadêmicos como adequado para o sucesso de sujeitos oriundos de grupos minoritários no acesso ao letramento hegemônico, mas também para a necessidade da prática desse modelo sempre que visualizarmos nesses sujeitos e em suas demandas o potencial de transformação da universidade em outros setores. Sugere-se a importância do incentivo ao trabalho criativo com a linguagem (FRANCHI, 1988, 1992, 2006a; ILARI, 2003). Aponta-se, ainda, para a pertinência do texto poético na transição entre práticas letradas diversas e para a necessidade de sua prática sempre que se tratar, de fato, da busca pelo letramento de caráter crítico.
\end{abstract}

Palavras-chave: Letramento Acadêmico. Tradução. Oralidade. Poético.

Recebido em:22/04/2017

Aceito em:08/10/2017

* Professora Associada do Departamento de Letras da UFSCar com atuação no PPGL/UFSCar e no TRADUSP. Líder do Grupo de Pesquisa LEETRA “Linguagens em Tradução" (CNPq). 


\section{Introdução}

Os Estudos da Tradução apresentam-se como campo interdisciplinar propício para se pensarem questões como aquela da escrita acadêmica e de seus elos com uma identidade em formação, mesmo porque, para além das postulações elitistas e essencialistas, centradas no que seria certo ou errado ao se produzirem textos escritos, cada vez mais, na sociedade multicultural e pluriétnica em que vivemos, a questão, aparentemente retórica, que Brian Street (1993) nos propôs, exige de nós respostas mais precisas: por que, em meio aos mais diversos letramentos, apenas um foi escolhido como aquele de prestígio?

A resposta tem sido rápida, porém já incapaz de resolver problemas ou propor soluções: seria uma questão voltada ao poder das elites, na linha do que Gnerre (1991) nos respondeu faz tempo. No momento atual, assim o compreendemos, os Estudos de Tradução podem trazer novas luzes para entendermos detalhes microtextuais e microssociais que podem ter ficado negligenciados nas abordagens de tendência macrossocial. Neste caso, temos, ainda, como nossa principal referência as postulações de Roman Jakobson (1969) em torno das diferentes possibilidades de tradução: interlinguística, intralinguística e intersemiótica. Talvez não seja apenas um detalhe ou coincidência o fato de se tratar de pensador que trazia em sua visada o texto poético. A questão se torna, no entanto, mais complexa e desprovida da aparente banalidade, quando nos lembramos do alerta de Henri Meschonnic (1982, p.13), poeta, linguista e tradutor, a respeito do papel que o ritmo deveria ter nos estudos da linguagem, como "uma parte que é talvez a mais importante", e da forma com que aponta para a necessidade de se construir uma teoria geral sobre o ritmo, com vistas a retirá-lo dos espaços mais restritos do texto literário ou da língua falada.

Aparentemente, não estaríamos longe da concepção de ritmo em Bakhtin, cuja obra vem se constituindo como uma das principais referências para os Estudos do Letramento, e em que ritmo, tom e valor apreciativo são vistos de forma interligada, mesmo porque também Meschonnic é enfático na referência à Ética e à Política. É fato, no entanto, que as reflexões advindas de Meschonnic contribuem, de preferência, para um enfoque de aspectos microtextuais (o léxico, a sintaxe, a prosódia), enquanto que, com Bakhtin, somos levados a refletir sobre o acento apreciativo (ideológico) que o ritmo comportaria. Fundado na crítica à 
forma superficial e limitada com que o ritmo via de regra é abordado nos estudos literários, apenas do ponto de vista da métrica, e baseando-se particularmente em Émile Benveniste, Meschonnic (1982, p. 216-217) propõe-nos esta definição: ${ }^{1}$

Defino o ritmo na linguagem como a organização das marcas pelas quais os significantes, linguísticos e extralinguísticos, (sobretudo no caso da comunicação oral) produzem uma semântica específica, distinta do sentido lexical, e que chamo de significação: isto é, os valores próprios a um discurso e apenas a ele. Essas marcas podem se situar em todos os níveis da linguagem: de tonicidade, de prosódia, léxico ou sintático. Constituem, juntas, uma paradigmática e uma sintagmática que neutralizam precisamente a noção de nível. Contra a redução comum do sentido ao léxico, a significação pertence a todo o discurso, está em cada consoante, em cada vogal que, como paradigma e como sintagma, desencadeia séries.

Vale lembrarmos, de passagem, que um dos problemas inerentes aos estudos dos gêneros do discurso, conforme amplamente sinalizado e debatido, constituise na tendência à compartimentação, ou seja, apesar de tanto nos referirmos ao "contínuo dos gêneros do discurso", ainda certa descontinuidade parece estar presente. Por isso mesmo, conforme ficará mais claro no decorrer deste trabalho, um de seus focos residirá na explicitação de elos que deem conta das lacunas responsáveis por tal compartimentação, apontando para formas de seu preenchimento. É digno de nota, aliás, que, com exceção do termo "narrativa", que pode aludir ao texto literário, embora não necessariamente, nenhuma menção é feita ao texto poético no quadro que nos propôs Marcuschi (2001).

Recorremos à tripartição proposta por Meschonnic (2008), de modo a entendermos melhor como nos referir de forma adequada às modalidades oral $\mathrm{e}$ escrita do discurso, i.e., como pensar melhor nas transições entre gêneros, e que papel o gênero do discurso poético poderia ter nesse entremeio. $O$ linguista francês nos propõe pensarmos em três modalidades de linguagem, e não apenas em duas: o falado ("le parlé"), o escrito ("l'écrit") e a oralidade ("l'oralité"). A "oralidade" estaria presente tanto na língua falada como na escrita, sendo mais propícia ou tendo maior visibilidade no texto poético ("l'écriture"), que comportaria a erotização da linguagem, isto é, as marcas do corpo na linguagem em sua subjetivação máxima.

1 Tradução minha, assim como dos demais excertos da obra de Meschonnic aqui presentes, com a qual dialogo, à medida que avanço possibilidades de derivação do que nela aparece esboçado e disperso. 
Partimos da percepção, em pesquisa efetuada no Departamento de Letras da Universidade Federal de São Carlos (UFSCar), de que, através de reflexões que incluíssem (a) o ritmo (seja o poético, seja o retórico), (b) os elos de transição entre textos de diferentes gêneros do discurso e (c) uma compreensão renovada sobre o que seria "oralidade", poderíamos compreender melhor as intuições dos que tanto condenam as marcas de oralidade na escrita acadêmica. Além disso, passamos a nos dar conta da necessidade de alertar para a importância de se desvendarem os elos de transição a que nos referimos, sempre que a pesquisa se localizar na área de ensino e aprendizagem de línguas, e particularmente com o foco no processo de escrita de textos diversos.

Habituamo-nos a pensar nas hibridizações (que sem dúvida existem), na heterogeneidade (que também sempre está presente), porém nenhuma dessas categorias, assim nos parece, nos propicia falar, com mais propriedade, de algo que quer estar na linguagem, que faz parte de sua ontologia, porém que é constantemente apagado, chamado a se apagar, constrangido ao apagamento. Sem dúvida, é certo, foi nossa pesquisa de viés participativo junto a graduandos indígenas que propiciou, na prática, a compreensão mais profunda de aspectos da teoria meschonniciana que buscávamos compreender e aprofundar. Não que necessariamente apenas esses sujeitos pudessem nos permitir essa compreensão; porém, é fato que são situações-limite as mais propícias a revelarem determinados fenômenos, ou a revelarem-nos de forma mais chamativa. Referimo-nos à presença do contingente indígena nas universidades como sendo uma situação-limite, em função da existência do hiato que separa as práticas de letramento em suas comunidades de origem daquelas típicas do ambiente acadêmico, alertando que, conforme será explicado adiante, não se tratava do fato de serem usuários de outras línguas nativas. De modo geral, para os graduandos indígenas na universidade em que se desenvolveu a pesquisa, e ao menos naquele período, a língua portuguesa era considerada L1, mesmo porque, conforme vimos podendo constatar, apenas poucas comunidades indígenas brasileiras ainda têm contato com a língua de seus ancestrais como língua primeira.

Entendemos ser fundamental mencionar, ainda, nesta Introdução, a importância da obra de Carlos Franchi (1988, 2006a e b), no que concerne a seu alerta para a fertilidade da tradução intralinguística que, em seus trabalhos, explorou sob o enfoque da "atividade epilinguística". Importante, também, a menção à homenagem de Ilari (2003) a Franchi, em trabalho em que, entre outros aspectos, 
trata de nos mostrar o quanto a linguagem possui mais de criativo, de heurístico, que de passivo, assujeitador ou estruturado. Como provas desse fenômeno, remetenos à energeia humboldtiana, à criação poética e à tradução.

\section{A oralidade, o ritmo e a subjetivação da linguagem}

É em Benveniste (1976) que Meschonnic se baseia para destacar, de forma enfática e ad nauseam o contraste entre os funcionamentos semiótico (centrado no signo, no produto e nas descontinuidades) e semântico da linguagem (fundado nos processos, no discurso e na continuidade). Questões de que, certamente, todos já temos algum conhecimento, porém frequentemente de forma descontínua, ou seja, como itens de nosso conhecimento, dos quais nos apropriamos intelectualmente, sem integrá-los carnal ou afetivamente, sem que eles se entranhem em nós, nos modificando enquanto pessoas, transformando nossa Ética, enquanto nossa maneira de nos relacionarmos e de vibrarmos energeticamente uns com os outros.

Vale lembrar, ainda, que, em seus diversos trabalhos, Meschonnic insiste em nos chamar a atenção para a forma com que, dentro dos estudos linguísticos, o texto poético tem sido deixado ou completamente de lado, ou no âmbito das excepcionalidades. $\mathrm{O}$ trabalho poético seria um trabalho diferenciado com a linguagem e, por isso mesmo, por mal compreendido, deixado à margem dos estudos linguísticos.

Conforme sabemos, nos Estudos da Linguagem, assim como presente em Discini (2006), a referência ao poético é feita com frequência com base na categoria bakhtiniana da carnavalização, o que, de toda forma, faz que, por um lado, o poético seja, ainda, colocado à margem e na dependência dos gêneros já sacralizados; por outro, que seja sempre considerado a partir de certa exterioridade em relação a um trabalho que, de fato, seria interno à linguagem. Haveria os gêneros do discurso em geral, e haveria a possibilidade de sua carnavalização. Em livros didáticos de Língua Portuguesa, muitas vezes a crônica e o poema são contemplados a título de exemplo do que sejam gêneros do discurso, porém prevalece o enfoque do descontínuo e da compartimentação. Mais recentemente, é certo, temos presenciado estudos em torno da forma de produção e circulação dos textos literários, assim como a presença mais marcada da ênfase na necessidade de utilização do texto poético em sala de aula. Entendemos, no entanto, que o 
porquê dessa ênfase e dessa necessidade não nos é, ainda, suficientemente claro do ponto de vista linguístico propriamente dito. Afinal, uma questão seria aquela de se referir à importância de estudos transdisciplinares, em que a Linguística e os Estudos Literários entrariam em diálogo; outra questão seria aquela própria aos estudos linguísticos em sua natureza, em que o signo poético passaria a ser visto em seu cerne. Por isso mesmo, aliás, os estudos em torno da produção e circulação de textos de teor literário ainda não nos dizem nada sobre o signo poético em si, talvez por não se tratar mesmo de seu foco. E com isso nada nos esclarecem sobre o papel do fazer poético em sua comunicação com a linguagem do cotidiano, nem tampouco sobre os elos que podem propiciar, quando se trata do processo de ensino e aprendizagem de línguas, ou mesmo, no caso a que nos dirigimos, do acesso à escrita acadêmica.

Nesse sentido, há algo de revolucionário, de ousado e muitas vezes até de incompreensível, ao menos à primeira vista, na proposta de Meschonnic, de que a linguagem poética seja vista ao lado da linguagem convencional, e em íntima comunicação com ela: o poema como a erotização da linguagem, como seu grau máximo de subjetivação. Escrever poeticamente é inserir-se na linguagem, transformando-a e sendo transformado por ela; nesse sentido, escrever poeticamente conecta-se, intimamente, com a afirmação meschonniciana de que pensar é transformar o pensamento (MESCHONNIC, 2008). Por outro lado, a linguagem poética seria dotada de aspectos prosódicos e rítmicos próprios, que lhe atribuem a força da linguagem, a linguagem potencializada, erotizada, portadora de marcas do corpo, fenômeno que conduz, conforme defendemos em Martins (2010; 2017), ao seu reconhecimento, quando presentes no texto que não se pretende poético, e particularmente no texto do círculo da atividade acadêmica, como marcas indesejáveis de oralidade na escrita.

Teremos, de toda forma, que entender por que esse fenômeno é considerado indesejável, além, é claro, de deixar mais nítido o que seja afinal "oralidade"; cabe, ainda, denunciar o fato de que, com essa alegação de que seriam indesejáveis "marcas de oralidade na escrita", apenas mudamos o foco da discriminação, mas o entendimento do que seja uma língua continuaria se valendo de fatores homogeneizadores, excludentes e discriminatórios. Não diremos elitistas, pois na medida em que venhamos, afinal, a compreender o que seja “oralidade", passaremos a ver que não é disso que se trata. Haveria uma discriminação e um sentido de exclusão ainda mais perverso, porque não se trata de uma questão de poder das elites, mas de uma questão que perpassa a Ética, e não proviria necessariamente das elites. Em certo sentido, uma questão de microfísica do poder. 
Linguagem é vida, linguagem é ritmo e vibração humana, linguagem é corporalidade e espiritualidade - podemos dizer isto, nesta entrada do século XXI, já não tão marcadamente intelectualista - de tal forma que a imposição de determinadas maneiras de dizer em detrimento de outras - vale notar que não estamos tratando aqui de assuntos ou de conteúdos, mas de maneiras de dizer -, em conjunto com a coerção ao apagamento das marcas de pessoa, de subjetividade, envolve violência e desrespeito à Ética, em seu sentido mais profundo.

Anotemos, aqui, a forma com que Meschonnic se refere à oralidade:

(...) só a escritura, como subjetividade máxima da linguagem, realiza plenamente a oralidade. Mesmo porque a oralidade não é, para mim, essa confusão com a fala, mas este modo de significação da linguagem em que o ritmo e a prosódia dominam, conduzem a dança. Na escrita e no falado. De fato, é essencialmente na escritura, no sentido literário da palavra, que se constata isso (MESCHONNIC apud ANCET, 1977, p.65).

Se é na escritura, enquanto escrita poética e literária, que se dá o grau máximo de subjetividade, o corpus de que pudemos tratar em Martins e Carvalho (2017), e ao qual fazemos referência indireta por falta de mais espaço neste momento, desvela essa erotização da linguagem às portas da academia, entranhada nos textos que não são necessariamente poéticos, mas embebidos dessa poesia enquanto oralidade, ou seja, enquanto linguagem erotizada, plena de sentimentos e de emoções.

Como se trata de algo com que nos deparamos a cada instante, porém frequentemente sem que atentemos para sua força (mesmo porque, em nosso entender, implica as dimensões mais ocultas do letramento), valerá a pena tratar de descrever esse fenômeno com mais detalhes (detalhes que se encontram dispersos na farta e prolixa obra de Meschonnic):

1. Estamos diante de uma derivação daquilo que Benveniste (1976) esboçou, particularmente em "Da subjetividade na linguagem" e "O aparelho formal da enunciação";

2. se queremos pensar num contínuo da linguagem, em seu sentido plástico, camaleônico, flexível, faz-se imprescindível a reflexão sobre a oralidade enquanto essa terceira dimensão da linguagem, presente tanto na modalidade falada como na escrita;

3. oralidade como a própria subjetivação da linguagem, na medida em que se apropriar de qualquer linguagem implica subjetivá-la; 
4. como subjetividade inerente à linguagem (própria de sua ontologia), trata-se de seu aspecto recitativo ("récitatif"), de sua rítmica, de uma forma específica de dizer-se "eu" diante de um "tu".

Intimamente relacionado à oralidade, Meschonnic define o ritmo como a organização da "parole" na "écriture", chamando a atenção para a escuta da panrítmica própria à oralidade, ou seja, à presença do corpo na voz, e para a necessidade de se analisar a força do dizer, e não só o significado do que é dito, mesmo porque este seria inapreensível sem aquela. Ritmo como organização do movente, do contínuo, a organização do movimento da palavra na escritura, a organização de um discurso por um sujeito, e de um sujeito por seu discurso; ritmo que engloba a prosódia e a entonação (no caso da fala); ritmo como operador do sujeito e do discurso, visto, nesse caso, em estado performativo, e retomando-se, com isso, a serialidade do texto, quando o sentido de um dizer não provém de cada uma das palavras, uma após a outra, mas de certa força ou modo aspectual que passa a interligá-las (MESCHONNIC,1995).

Não seria excessivo lembrar que, se as cadências, ritmos e ressonâncias se impregnam nos textos, sejam orais ou escritos, isso se dá pela continuidade com que aspectos presentes na realidade sócio histórica e nos seus sujeitos deixam suas marcas nos produtos semióticos que aí circulam, dentro de uma relação de continuidade entre a linguagem cotidiana e aquela da escritura, não fazendo sentido, assim, a oposição dicotômica entre o oral e o escrito, entre a língua falada e a escrita ou, ainda, entre textos poéticos e não poéticos. Retomamos mais algumas palavras de Meschonnic (2010, comentários nossos entre colchetes), lembrando que as considerações do linguista francês com relação à tradução interlinguística são também, em nosso entender, aplicáveis à tradução intralinguística, ou seja, aos processos de transposição intergenérica na mesma língua:

Chamo então as traduções [podemos aqui pensar na tradução intralinguística, do texto carregado de erotização para o texto acadêmico] de apagantes, já que elas apagam o ritmo e o significante (...) O problema poético [e ético] é dessemiotizar para fazer entender uma semântica sufocada pela semiótica, uma semântica serial. (...) O significante, na sua semântica serial é a força. Traduzir/escrever é traduzir a força. (...) mas a força é o que leva e traz o sentido. É o movimento do sentido. Nada mais simples. A coerência do continuum, contra a coerência do signo (...) É toda a diferença entre atividade e produto (...) Está claro, então, que escrever supõe repensar toda a teoria da linguagem. E 
que traduzir é a prática que, mais do que qualquer outra, coloca-a em jogo. A conclusão é que o desafio do traduzir é transformar toda teoria da linguagem. Sim, uma verdadeira revolução cultural. (MESCHONNIC, 2010, p.19-21)

Cada vez mais, por isso tudo, pareceu-nos necessário destacar, não a tão alegada dificuldade que os estudantes teriam de lidar com a linguagem acadêmica, mas a dificuldade ou intolerância - paradoxal - da academia para com uma linguagem que se apresente em sua força de subjetividade. Sem espaço aqui para nos focarmos em exemplos de textos produzidos pelos graduandos indígenas, remetemos a Martins e Carvalho (2017), lembrando a constância com que esses textos se alinhavam ao gênero do discurso do relato ("récit"), com suas marcas de subjetividade, assim como caracterização léxico-sintática e rítmica peculiar.

Faz-se importante destacar, de toda forma, que, se é fato que o modelo dos Letramentos Acadêmicos, com os quais nos alinhamos e que também defendemos (conforme será explicitado adiante), dão conta de uma gama de fatores, no que tange, no entanto, a aspectos propriamente linguísticos, podemos correr o risco da mescla entre o modelo cognitivo e o dos Letramentos Acadêmicos, sempre que tratarmos de forma compartimentada os aspectos sócio-ideológico-culturais, de um lado, e os linguísticos de outro. Explicamo-nos: não se trata de lidar conceitualmente com a vertente crítica do letramento, se não nos dermos conta de que, para se realizar de forma plena, esse aspecto crítico necessita travestir-se de forma, de força de linguagem, de ritmo. Em certo sentido, diríamos, trata-se de trazer para o âmbito dos estudos linguísticos algo semelhante àquilo com que a filosofia já vem se debatendo desde Merleau-Ponty (1964), passando, antes, por Spinoza e Humboldt: se no âmbito da Filosofia passou-se a questionar a possibilidade do acesso à verdade e à conceituação a esse respeito sem levar em consideração o papel das próprias palavras utilizadas para essa reflexão, na Linguística, conforme defendemos, não acederemos a uma visão crítica a respeito da linguagem - e junto com ela, a uma proposta crítica de ensino de línguas - sem passar pelo manuseio das palavras em seu quefazer poético.

Apresentamos aqui, antes de passar para o próximo item, e a título de ilustração do corpus ao qual fazemos referência, excerto de texto de vestibulando indígena do ano de 2009: ${ }^{2}$

A terra é uma vivência amorosa que estamos vivendo no cotidiano, entre os ventos, o mar, a natureza e os animais. Entretanto,

2 Agradecemos à Fundação VUNESP, que nos disponibilizou as redações para a finalidade de pesquisa. Lembramos que foi feita revisão convencional do texto de forma a não expor os sujeitos de pesquisa. 
temos direitos a serem respeitados diante dos seguintes deveres: principalmente, a terra precisa da gente para que possamos sobreviver e cuidar, por isso urge respeitar o meio ambiente. Atualmente a forma não é a mesma que o antigo, a terra vem sofrendo, gritando e ninguém ouve de ser perdoado.

Como breve observação, chamamos a atenção, neste caso, para a forma com que, em se tratando da circunstância de escrita de redação de vestibular, seria de se esperar texto de caráter argumentativo com o predomínio da estratégia do discurso; mesclam-se, no entanto, elementos próprios à estratégia do "récit", assim como uma escolha vocabular mais típica de textos de caráter poético. É certo, além disso, que as opções sintático-semânticas comportam uma rítmica específica, uma panrítmica que atribui ao texto certa nuance muito frequentemente caracterizada pejorativamente em função da presença de "marcas de oralidade na escrita". Encontra-se, de toda forma, certa aspectualização que, em nosso entender, exatamente por se relacionar com a presença da subjetivação na linguagem, não se trataria de apagar, mas de traduzir.

\section{A prática de pesquisa a iluminar a teoria ${ }^{3}$}

Alguns esclarecimentos se fazem necessários. Não estamos postulando que os estudantes chegam à universidade portadores de uma linguagem ideal, mas, sim, que a linguagem que trazem é portadora de marcas positivas, e não negativas, de uma força que quer se manifestar na linguagem, que necessita de tradução - e não de apagamento e substituição - e que não lhes pode ser negada: decerto, não será com o apagamento e com a semiotização (nos termos de Meschonnic) de sua linguagem que poderemos contribuir para uma formação ética e cidadã, ou, de resto, para uma escrita dotada de autonomia e de força de linguagem. Nesse sentido, a presença indígena nas universidades brasileiras nos alerta, na verdade, para a necessidade de um trabalho com a linguagem que certamente não tange apenas a eles.

Observamos, de passagem, que não se trataria de buscar resolver essa questão da transição às práticas letradas acadêmicas por vias de processos de retextualização

3 Reconhecemos a importância de apoios FAPESP 2009/13871-4 e 2015/24353-5, que tornaram viável parte significativa dos resultados de pesquisa apresentados aqui. Lembramos, ainda, a autorização do Comitê de Ética para a pesquisa, sob o número 17948113.7.0000.5504 do Certificado de Apresentação para Apreciação Ética (CAAE). Mais detalhes a respeito desta pesquisa aparecem em Martins (2014), assim como em Martins e Carvalho (2017). 
(na substituição de determinadas palavras, que seriam consideradas como pertencentes ao âmbito da oralidade, ou portadoras de "marcas de oralidade"); é nesse ponto que defendemos, em lugar deles, os processos de tradução, no que implicam levar-se em consideração a força da linguagem, a panrítmica, a semântica serial. Traduzir, assim, nesse caso da transposição de textos de um gênero a outro (no caso em pauta, do gênero do récit para os gêneros do discurso acadêmico), comportaria procedimentos próprios da tradução literária, em que os critérios de fidelidade vêm sendo repensados, considerando-se que, mais importante que uma tradução literal, que fosse substituindo palavra a palavra, seria levar em consideração o ritmo, a prosódia, a força da linguagem, de forma a transpô-la para a outra língua. Frequentemente, no entanto, conforme sabemos, quando tratamos da transposição/tradução intergenérica, o critério da dicotomização subjetividade/ objetividade encontra-se sobremaneira presente.

Não se trataria, assim de dessubjetivar a linguagem; ao contrário: tratarse-ia de dessemiotizá-la. Não se trataria, portanto, de eliminarmos as marcas de oralidade da escrita; tratar-se-ia, em vez disso, de traduzi-las; já que não se trata de traduzir apenas o léxico, mas de levar-se em conta a energeia, a força da linguagem, sua panrítmica - sem dúvida, um trabalho bastante complexo a se empreender sobre a linguagem, complexo e promissor, complexo e profético, já que aquilo de que necessitamos, de forma a retirar a linguagem de sua condição de asfixia, é retirá-la dos processos e procedimentos de sacralização.

Passamos a relato sucinto de alguns detalhamentos da pesquisa que conduzimos, na Universidade Federal de São Carlos, a partir do ano de 2009, e que teve como foco a forma de apropriação do letramento acadêmico por parte de graduandos indígenas, assim como a complexa forma de transição que vivenciam a partir dos gêneros do discurso que praticam em suas comunidades de origem. É digno de nota o fato de que, segundo o censo de ensino superior apresentado pelo Instituto Nacional de Estudos e Pesquisas Educacionais Anísio Teixeira (INEP) em 2013, do total de 6.739 .689 brasileiros matriculados em instituições públicas e privadas brasileiras, em cursos presenciais e a distância, 9.756 matrículas eram de estudantes indígenas. Também de acordo com o INEP, o número de indígenas matriculados no ensino superior veio a crescer 255\% entre os anos de 2010 e 2016. O contato com os estudantes indígenas na universidade de que tratamos deu-se a partir de suas participações em Atividades de Extensão coordenadas pela autora deste trabalho, enquanto professora de Departamento de Letras. Por meio 
dos encontros, houve a oportunidade de conhecer um pouco mais do universo dos graduandos indígenas, de sua forma de se expressar em língua portuguesa, assim como de seus impasses em torno da escrita acadêmica. Vale destacar, no entanto, que, no caso de que tratamos, a língua portuguesa era L1 para a maioria dos graduandos indígenas, contrariamente ao que supunham, de início, os próprios gestores da secretaria local de Ações Afirmativas.

É importante enfatizar, conforme Martins e Carvalho (2017), que, no que tange à compreensão do acesso à escrita acadêmica, até a década de 1980 prevaleceu a vertente cognitiva, de resto também predominante à época na área de ensino e aprendizagem de línguas em geral, e de toda forma ainda bastante presente nos diversos níveis de ensino. Lea e Street (2006) referem-se, nesse caso, a três perspectivas: a cognitiva, que podemos considerar como pertencente a um enfoque algorítmico, i.e., centrado em estratégias e competências linguísticocognitivas consideradas necessárias para a elaboração de textos; aquela de cunho interacional, que prevê a socialização acadêmica, porém ainda não comporta uma visada crítica, ou seja, de cunho sociológico mais abrangente; e a terceira, dos Letramentos Acadêmicos, de caráter mais complexo e crítico.

O primeiro modelo, de modo geral mais centrado no professor e na forma com que pode conduzir seus alunos à apropriação de determinadas competências escolares ou acadêmicas, implica o reconhecimento de habilidades individuais relativas ao domínio da língua formal, bastante presente, entre nós, nos cursinhos preparatórios para o vestibular, por exemplo. Podemos associá-lo, ainda, ao que Street (1993) veio a denominar modelo autônomo do letramento, já que centrado na escrita e nas habilidades que lhe seriam inerentes de forma relativamente isolada. O segundo modelo, bastante presente em nossas universidades, mesmo naquelas em que vigoram ações afirmativas, mostra-se redutor, se sujeito ao crivo de uma análise contemporânea que se dê conta de questões etnocêntricas, já que parte do princípio de que a socialização acadêmica, em si, seria a chave para a superação de certa defasagem cultural de que minorias étnicas seriam portadoras. Baseia-se, assim, no pressuposto da necessidade de aculturação em discursos e disciplinas determinadas, para que suas peculiaridades sejam apreendidas e, desse modo, os graduandos sejam capazes de se apropriar do discurso acadêmico hegemônico com êxito. Note-se que, de toda forma, este modelo comporta a presunção do déficit cultural, já criticado por Soares (1986), entre outros, na década de oitenta.

O terceiro modelo, aquele dos Letramentos Acadêmicos, é considerado pelos autores “(...) o que melhor leva em conta a natureza da produção textual do 
aluno em relação às práticas institucionais, relações de poder e identidades (...), consegue contemplar a complexidade da construção de sentidos, ao contrário dos outros dois modelos" (LEA; STREET, 2006, p.546). É digno de nota o fato de que este modelo se coaduna com a abordagem ideológica do letramento (Street, 1993), na medida em que comporta viés crítico, o qual se dirige até mesmo ao círculo da atividade acadêmica, de forma a desvelar os aspectos ocultos com que se constroem os discursos nesse âmbito. Segundo Corrêa (2011) ao criticar os demais modelos, Lea e Street buscam apontar para uma dimensão do letramento ainda não suficientemente explorada, chamando a atenção para a “(...) presunção sobre a transferência automática de um contexto a outro", assim como para o “(...) ocultamento de que as próprias habilidades cognitivas relativas à escrita são produto da apreensão do funcionamento da escrita e do letramento em contexto" (Corrêa, 2011, p.339).

Este foi o modelo com o qual nos alinhamos, em princípio, no decorrer dos encontros promovidos em atividades extensionais, fazendo-o de forma situada, ou seja, levando em consideração os fatores contextuais e múltiplos de nossa realidade pluriétnica. Vale notar, no entanto, que muito embora façamos referência à teorização apresentada por Lea e Street, mostrando de que maneira nossa prática se alinhou à vertente defendida por eles, isso não se deu, de toda forma, como aplicação de uma teoria a nossa prática, ou como forma de testagem de uma teoria. Nossa principal referência centrava-se na epistemologia freiriana (FREIRE, 1976; 1978), que prevê a horizontalidade nas relações professor / aluno, assim como a inter-relação entre acesso à escrita e conscientização, de tal forma que pensar nos Letramentos Acadêmicos na linha de Lea e Street deu-se como confluência com um pensamento com o qual já se tinha familiaridade, em seus contornos principais, nos Círculos de Cultura coordenados no final da década de setenta, em plena vigência do AI5 em nossas terras. ${ }^{4}$

Dessa forma, no caso das atividades extensionais, foi priorizado o diálogo horizontal, dentro da proposta freiriana, em que todos aprendem juntos, professores e alunos. Isso porque, mais do que em outros casos, cabia a professores e pesquisadores, nessa circunstância sui generis da presença indígena na universidade, escutar seus alunos, de modo a cada vez entender melhor quem eram seus interlocutores, portadores de culturas diversas e, fundamentalmente,

4 A autora coordenou Círculo de Cultura em Associação do Bairro de Novo Osasco (Osasco/SP) no ano de 1978 . 
de uma outra perspectiva a respeito da História do Brasil. Em função disso, os encontros eram fundamentalmente dirigidos a sessões de filmes e debates em torno da temática indígena, tornando-se o trabalho com os textos escritos atividades complementares. Essa forma de lidar com atividades de ensino e de extensão atraía esses novos graduandos, em parte porque as sessões haviam se tornado um ponto de encontro de indígenas de diferentes departamentos da universidade, em parte porque sabiam que ali suas falas eram valorizadas e levadas em consideração.

Em Martins e Carvalho (2017), há referência a relatos de graduandos indígenas no decorrer das atividades extensionais, em que foi destacada a discriminação por parte de estudantes não indígenas, como aquele apresentado por caloura do curso de Psicologia acerca de evento no restaurante universitário: "Eu estava na fila com minha amiga, quando chegou um menino que perguntou o que eu estava fazendo aqui, porque não é lugar pra índio e também questionou se eu vou conseguir acompanhar o curso. Eu me senti tão mal, como se ele não me visse como gente". A partir das palavras da aluna, foi iniciado um longo debate sobre questões culturais que abarcam a sociedade em geral, e todos os alunos indígenas argumentaram que a universidade precisa de mudanças para melhor recebê-los, pois as barreiras socioculturais ainda são fortes e prejudicam ou comprometem de forma definitiva sua permanência.

É interessante lembrar a forma com que Freire se furtava a referir-se a sua proposta como a uma metodologia de ensino, preferindo entendê-la como epistemologia-escolha que aponta para a própria impossibilidade de uma aplicação, já que a perpassa (assim como no caso da proposta de Meschonnic) o anseio pela Ética, pela Estética e pela Política. Entendemos, de resto, que não se pratica ou aplica algo - dentro da profundidade e complexidade aqui envolvidas - de que já não estejamos profundamente embebidos e convencidos de antemão. É fato, assim, que a maneira de abordar os Letramentos Acadêmicos, nesse caso, levava em consideração a importante perspectiva do fortalecimento daqueles a quem, de alguma forma, havia sido negada a voz. Por isso mesmo, não faria sentido, nesse contexto, nem a vertente cognitiva, apenas centrada em determinados aspectos dos textos (coesão, coerência, adesão a regras gramaticais), mesmo porque seria mais uma forma de silenciamento ou, ao menos, de imposição de traços de uma cultura sobre a outra; nem a vertente interacionista, que pressupõe a necessidade que os recém-chegados teriam de conviver com a cultura do outro de forma a melhor assimilá-la - na qual é visível certa presunção de superioridade étnica e cultural. 
Faz-se importante ressaltar, ainda, a ressalva frequente no contexto universitário, particularmente com relação aos graduandos que ingressam por sistema de cotas, que chegariam despreparados e com sérias defasagens em relação ao letramento acadêmico. Visão que, em nosso entender, requer, para a solução da problemática que implica, uma abordagem crítica - naquele sentido que a Escola de Frankfurt construiu, de uma abordagem abrangente, que relaciona as partes com o todo que as circunda - , a qual desvele as questões de poder e as normas restritivas que estão em jogo, de tal forma que, nesse âmbito, ao apropriar-se das novas modalidades de escrita, o graduando o faça, enquanto simultaneamente constrói uma visão crítica a seu respeito, e não de forma idealizada.

\section{As marcas de oralidade e os aspectos ocultos do letramento}

Segundo Corrêa (2011), o presumido social, i.e., o aspecto pressuposto ou oculto nas práticas sociais, abarca toda a produção de sentido, estendendo-se, também, aos gêneros do discurso (no que contêm de estrutura, temática e estilo peculiares). Fundado em pesquisa com textos de estudantes pré-universitários, o autor destaca que o segundo modelo mencionado acima, o de socialização escolar, conduz os estudantes a buscarem adaptar, de forma relativamente artificial, suas produções ao que lhes é solicitado no exame vestibular, centrados em determinados padrões de estrutura e de linguagem. O terceiro modelo - aquele dos Letramentos Acadêmicos -, em contrapartida, tentaria explicar o funcionamento da escrita e do contexto de letramento com base nas "dimensões ocultas", visto que abarca identidades, relações entre os sujeitos, questões culturais, de poder e de autoridade.

Martins (2008), à sua maneira, faz referência a fenômeno semelhante, ao mencionar a forma com que Goody (1968) aludiu ao "letramento restrito" próprio de sociedades tradicionais e relativamente fechadas, em que alguns aspectos da linguagem escrita tornam-se restritos ao acesso de uma minoria, que o trata de forma naturalizada, ou seja, como se não houvesse regras ou chaves específicas para sua apropriação. Martins (2009, comentários nossos em colchetes) alude, através do seguinte relato, às dimensões ocultas ou restritas do letramento:

(...) fiquei chocada quando, paradoxalmente, Jessica (nome fictício), uma pós-graduanda que fazia parte de nosso Grupo de Pesquisa, disse: "Aqui na universidade a maioria dos professores 
parece esconder seu conhecimento". Novamente, poderia parecer apenas uma reclamação típica de estudantes, mas como estava atenta a essas questões relacionadas com o letramento restrito ["restricted literacy"] e com suas dimensões ocultas ou secretas, comecei a conceber a ideia de um contínuo de gêneros do discurso [que complementaria o contínuo informal/formal], que iria de suas dimensões mais ocultas às menos ocultas, e que se torna mais reconhecível no caso das pessoas consideradas analfabetas que ingressam no universo letrado, existindo, no entanto, em outras situações, e também no nível universitário (MARTINS, 2009, p.116, tradução nossa).

Retomamos, a propósito, a reflexão em torno do que seja oralidade, assim como do que sejam as pretensas marcas de oralidade na escrita, para lembrar que, talvez, no âmbito da pesquisa em torno do letramento acadêmico, ainda não se tenha tornado suficientemente nítido o que está em pauta nesse caso; também com vistas a chamar a atenção para esse aspecto oculto ou presumido do letramento, em que certa maneira de se pronunciar torna-se negada, sem que se conheçam as raízes inerentes a essa negação, ou, inversamente, sem que se compreendam as origens daquilo que necessitaria ser negado.

Entendemos, assim, que talvez estejamos, neste caso, diante de dimensões de tal modo ocultas, que ainda estão abertas a pesquisa, trazendo-nos, em certo sentido, de volta à pergunta que se colocou logo de início - por que, diante de tantos letramentos, apenas um deles adquiriu estatuto de prestígio? - à qual se adiciona outra pergunta de teor ainda aparentemente enigmático: por que seria vedada a entrada do corpo e de suas derivações na escrita acadêmica?

Alertamos, de resto, para o fato de que, provavelmente, é a mistura entre fenômenos implícitos à escrita com fenômenos próprios à leitura - e considerase fundamental a separação, ao menos analítica, de ambos, de forma a entender melhor as nuances que os caracterizam - que conduz à presunção simplificadora das marcas de oralidade na escrita; ou seja, se para aquele que consome textos, que os lê, podem chamar a atenção, em princípio, as pretensas marcas da oralidade na escrita, talvez pelo fato de, inadvertidamente, priorizar o produto da escrita, em detrimento de seu processo, não é dessa forma, à moda de um pastiche, que se constrói o texto. Essa presunção implicaria, é certo, o demérito ou simplificação extrema do trabalho do escrevente, ao supor que ele traz para a escrita certo hábito de fala, atribuindo ao texto, de forma inadvertida, aspecto heterogêneo ou híbrido.

Mais interessante e profundo será pressupor o princípio heurístico em sua força 
criativa de energeia, já que, se, na leitura, podemos passar a priorizar o produto, o ergon, talvez por conta de certa "ruse" (trapaça ou artifício) da linguagem (mesmo que a leitura em si envolva um processo ou um processamento), na escrita, no entanto, é a energeia, enquanto atividade produtiva, que está em jogo. Energeia que não se traduz, apenas, como atividade em seu sentido mais convencional, mas como corporeidade, como presença histórica do sujeito na escrita.

\section{Considerações finais}

Os dados apresentados em mais detalhe em Martins e Carvalho (2017), assim como sua análise detida, apontam para uma problemática complexa e abrangente, que, se diz respeito a boa parcela do contingente universitário que se debate às voltas do domínio da escrita acadêmica, mesmo no âmbito dos estudos de pósgraduação, também, implicitamente, diz respeito a uma escrita bem-comportada, porém sem marcas de subjetividade, que domina a academia sem que gere a preocupação que, por outros motivos, lhe seria devida. Nesse sentido, o alerta de Franchi (2006b) com relação a textos de crianças dos primeiros anos do Ensino Fundamental, ao mostrar que seria mais digno de preocupação o texto de uma criança, bastante impecável no que tange ao respeito à norma culta, porém desprovido de força de linguagem - esse alerta é extensivo à escrita acadêmica.

A pesquisa a que fazemos referência foi desenvolvida no contexto acadêmico, com base nas constrições ali presentes, e com vistas a contribuir, de forma ágil, para o maior êxito dos graduandos indígenas nesse meio. De toda forma, dentro de um propósito emancipador, sabemos que seria desejável mais do que isso. Acredita-se, idealmente, que o trabalho mais livre, voltado a produções que se aproximassem do teor literário em função da criatividade da linguagem em seu aspecto formal, na linha das oficinas de escrita criativa, pudesse trazer resultados mais interessantes e promissores a longo prazo, na medida em que houvesse maior reforço do trabalho criativo, imaginativo, portador da subjetivação da linguagem, de uso de um léxico variado e abrangente, em que se trabalhasse com as mais diversas formas e gêneros de textos, e não somente com os textos de escrita acadêmica.

Interessante, de resto, seria conduzir os graduandos à observação da forma com que cada modalidade textual comporta seu ritmo próprio, seja ele do âmbito 
da Retórica, seja da Poética. Assim como da forma com que o sentido de um texto deriva, de preferência, de sua força de linguagem, da panrítmica que lhe é própria, e não de cada palavra isoladamente. Percebe-se, através destas observações, a forte interface existente entre, por um lado, a prática de tradução intralinguística e intergenérica, que insira em seu escopo o texto de teor poético, i.e., a escritura literária, e, por outro, a construção sólida de uma teoria da linguagem, à qual, por sua vez, cada graduando poderia ter acesso ao fazer parte desse processo de manipulação da linguagem, e não na forma da recepção e assimilação de conteúdos pré-formatados.

Temos que não existe linguagem isolada, podendo concluir, a partir dessa constatação, que a escrita acadêmica não poderia ser apreendida por si própria, mas sempre em comunicação com uma diversidade de outras escritas, dotadas de efeitos de sentido de maior ou menor subjetividade, porém sempre subjetivadas, sem o que deixariam de ser linguagem enquanto atividade constitutiva, para ser linguagem de caráter repetitivo, redundante e pouco criativo, linguagem estereotipada. É no âmbito desse contínuo de gêneros do discurso, atravessado sempre pela presença da oralidade em sua panrítmica e em sua força de subjetivação, que sugerimos a inserção de textos de teor poético os mais diversos enquanto elos ainda ausentes, ou lacunas a serem preenchidas, de forma a superarmos, de fato e de forma mais definitiva, dicotomizações ainda prevalecentes, como aquelas entre o oral e o escrito, o poético e o não poético, o objetivo e o subjetivo, o intelectivo e o emotivo. 


\title{
Academic literacy and orality: rethinking terminology in the light of indigenous presence at Brazilian universities
}

\begin{abstract}
This paper bears reflections based on research on academic literacy taking into consideration Brazilian contemporary reality in view of indigenous attendance at universities. We founded research, in part, on New Literacy Studies and, in a complementary way, on some conceptions drawn from Translation Studies. Research was developed in the years of 2012-2015 based on procedures and strategies similar to those present in what Lea \& Street (2006) call "Academic Literacies Model". Centered on empowering and participative methodology (CAMERON, 1992), our objectives were: a) understanding the transition/translation from the account discourse genre ("récit") to academic discourse genres; b) to enhance indigenous undergraduate students' access to academic literacy practices together with a necessary metaconsciousness on such a process. Results point not only to Academic Literacies Model as adequate for the success of subjects from minority groups to hegemonic literacy, but also to the necessity of the adherence to such a model whenever one visualizes in these subjects and in their demands the potential of transformation of university in other sectors. We suggest the importance of motivating creative work with language (FRANCHI, 1988, 1992, 2006a; ILARI, 2003). We also point to the pertinence of poetic texts in the transition between different literacy practices and to the necessity of working with such texts whenever a search for critical literacy is at stake.
\end{abstract}

Keywords: Academic Literacy. Translation. Orality. Poetics.

\section{Referências}

ANCET, Jacques. Entretien avec Henri Meschonnic. Prétexte, n. 12, 1977.

BENVENISTE, Émile. Problemas de Linguística Geral. São Paulo: Nacional / Edusp, 1976.

CAMERON, Deborah et al. Researching language: issues of power and method. London/ New York: Routledge, 1992.

CORRÊA, Manoel Luiz Gonçalves. Heterogeneidade da escrita: a novidade da adequação e a experiência do acontecimento. Filologia e linguística portuguesa, 2006.

CORRÊA, Manoel Luiz Gonçalves. As perspectivas etnográfica e discursiva 
no ensino da escrita: o exemplo de textos de pré-universitários. Revista da ABRALIN, v. eletrônico, n. especial, 2., p. 333-356, 2011.

DISCINI, Norma. Carnavalização. In: BRAIT, Beth. Bakhtin: outros conceitoschave. São Paulo: Contexto, 2006.

FRANCHI, Carlos. Criatividade e Gramática. In: SÃO PAULO. Secretaria da Educação. CENP. Criatividade e gramática. São Paulo, SE/CENP, 1988.

FRANCHI, Carlos. Linguagem - Atividade Constitutiva. Cadernos de Estudos Linguísticos, Campinas, v. 22, p. 9-39, jan./jun. 1992.

FRANCHI, Carlos. Criatividade e Gramática. In: POSSENTI, Sírio (Org.). Mas o que é mesmo gramática? São Paulo: Parábola, 2006a.

FRANCHI, Carlos. Mas o que é mesmo gramática? In: POSSENTI, Sírio (Org.). Mas o que é mesmo gramática? São Paulo: Parábola, 2006b.

FREIRE, Paulo. Educação como prática da liberdade. Rio de Janeiro: Paz e Terra, 1976.

FREIRE, Paulo. Pedagogia do oprimido. Rio de Janeiro: Paz e Terra, 1978.

GOODY, Jack. Literacy in traditional societies. Cambridge: Cambridge University Press, 1968.

GNERRE, Maurizzio. Linguagem, escrita e poder. São Paulo: Martins Fontes, 1991.

ILARI, Rodolfo. Linguagem - Atividade Constitutiva (Ideias e Leituras de um Aprendiz). Revista Letras, Curitiba, n. 61, especial, p. 45-76, 2003.

JAKOBSON, Roman. Aspectos linguísticos da tradução. In: Linguística e comunicação. São Paulo: Cultrix, 1969.

LEA, Mary R.; STREET, Brian. Student Writing in higher education: an academic literacies approach. Studies in Higher Education. London, v. 23, n. 2, p. 157-16, June 1998.

LEA, Mary R.; STREET, Brian. The "Academic Literacies" model: theory and applications. Theory into Practice, v. 45, n. 4, p. 368-377, 2006.

MARCUSCHI, LuizAntonio. Da fala para a escrita: atividades de retextualização. São Paulo: Cortez, 2001.

MARTINS, Maria S. Cintra. Avanços e retrocessos nas propostas de ensino de Língua Portuguesa: questões de ideologia e de poder. Linguagem em (Dis)curso, v. 8, n. 3, Tubarão: Unisul, p. 519-539, 2008. 
MARTINS, Maria S. Cintra. The continuum illiterate-literate and the contrast between different ethnicities. In: BAZERMAN, Charles et al. (Org.). Traditions of Writing Research. New York: Routledge, 2009.

MARTINS, Maria S. Cintra. Ethos e estilo em textos produzidos na esfera acadêmica. In: SERRANI, Silvana (Org.). Letramento, Discurso e Trabalho Docente: uma homenagem a Angela Kleiman. São Paulo: Ed. Hedra/Ecidade, 2010 .

MARTINS, Maria S. Cintra. Letramento e Identidade: as fronteiras da tradução. Revista Scripta, Belo Horizonte, v. 32, 2013.

MARTINS, Maria S. Cintra. Aspectos tradutórios do letramento: ressonâncias rítmicas. Revista Delta, São Paulo: EDUC, 2017.

MARTINS, Maria S. Cintra; CARVALHO, Gláucia R. G. Escrita acadêmica e identidade à luz da presença indígena na Universidade Federal de São Carlos. São Carlos: EDUFSCar/FAPESP, 2017.

MERLEAU-PONTY, Maurice. Le visible et l'invisible. Paris: Gallimard, 1964. MESCHONNIC, Henri. Politique du rythme. Politique du sujet. Lagrasse: Verdier, 1995.

MESCHONNIC, Henri. Dans le bois de la langue. Paris: Éditions Laurence Teper, 2008.

SOARES, Magda. Linguagem e escola: uma perspectiva social. São Paulo: Ática, 1986.

STREET, Brian. Cross-cultural approaches to literacy. Cambridge: Cambridge University Press, 1993. 